\title{
Impact of Remdesivir on the Treatment of COVID-19 During the First Wave in Spain
}

\author{
Alejandro Soriano · Rocío Montejano · José Sanz-Moreno • \\ Juan Carlos Figueira · Santiago Grau • Robert Güerri-Fernández • \\ Antonio Castro-Gómez · Inés Pérez-Román · Álvaro Hidalgo-Vega • \\ Almudena González-Domínguez
}

Received: April 21, 2021 / Accepted: May 20, 2021 / Published online: June 12, 2021

(c) The Author(s) 2021

\section{ABSTRACT}

Introduction: Spain was one of the most affected countries during the first wave of COVID19, having the highest mortality rate in Europe. The aim of this retrospective study is to estimate the impact that remdesivir-the first drug for COVID-19 approved in the EU-would have had in the first wave.

Methods: This study simulated the impact that remdesivir could have had on the Spanish

Supplementary Information The online version contains supplementary material available at https:// doi.org/10.1007/s12325-021-01804-9.

\section{A. Soriano}

Unit of Infectious Diseases, Hospital Clinic,

Barcelona, Spain

R. Montejano

Unit of Infectious Diseases, Internal Medicine Department, La Paz University Hospital, Madrid, Spain

J. Sanz-Moreno

Unit of Infectious Diseases, Internal Medicine

Department, Principe de Asturias University

Hospital, Madrid Spain

J. C. Figueira

Intensive Care Department, La Paz University

Hospital, Madrid, Spain

S. Grau

Pharmacy Department, Hospital del Mar, Barcelona, Spain
National Health System (SNHS) capacity (bed occupancy) and the number of deaths that could have been prevented, based on two scenarios: a real-life scenario (without remdesivir) and an alternative scenario (with remdesivir). It considered the clinical results of the ACTT-1 trial in hospitalized patients with COVID-19 and pneumonia who required supplemental oxygen. The occupancy rates in general wards and ICUs were estimated in both scenarios.

Results: Remdesivir use could have prevented the admission of 2587 patients $(43.75 \%)$ in the ICUs. It could have also increased the SNHS capacity in 5656 general wards beds and 1700

\section{R. Güerri-Fernández}

Infectious Diseases Department, Hospital del Mar, Barcelona, Spain

\section{A. Castro-Gómez}

Gilead Sciences, Madrid, Spain

I. Pérez-Román · A. González-Domínguez ( $₫)$

Pharmacoeconomics and Market Access

Department, Weber, Madrid, Spain

e-mail: almudena.gonzalez@weber.org.es

Á. Hidalgo-Vega

Economy and Health Research Seminar, University of Castilla-La Mancha, Toledo, Spain

\footnotetext{
Á. Hidalgo-Vega

Foundation Weber, Madrid, Spain
} 
ICU beds, showing an increase in the number of beds available of $17.53 \% \quad(95 \% \quad$ CI $3.98 \%-24.42 \%)$ and $23.98 \% \quad(95 \% \quad$ CI $21.33 \%-28.22 \%)$, respectively, at the peak of the occupancy rates. Furthermore, remdesivir use could have prevented 7639 deaths due to COVID-19, which implies a $27.51 \%$ reduction (95\% CI 14.25\%-34.07\%).

Conclusions: Remdesivir could have relieved the pressure on the SNHS and could have reduced the death toll, providing a better strategy for the management of COVID-19 during the first wave.

Keywords: COVID-19; Remdesivir; ICU; Bed occupancy; Spain

\section{Key Summary Points}

Why carry out this study?

Spain was one of the European countries most affected by COVID-19, with $>1.7$ million cases and close to 50,000 deaths by the end of 2020 . The pandemic has caused the biggest recent health crisis, placing an unprecedented healthcare burden on the Spanish National Health System.

Remdesivir is the first drug indicated for the treatment of COVID-19. It improves the clinical status of hospitalized patients with COVID-19 and pneumonia, who require supplemental oxygen.

Therefore, the aim of this study is to estimate the impact that remdesivir could have had in the first wave in Spain.

\section{What was learned from the study?}

Remdesivir could have relieved the pressure on the SNHS and reduced the death toll.

Remdesivir use could have provided a better strategy for the management of COVID-19 during the first wave.

\section{DIGITAL FEATURES}

This article is published with digital features, including a summary slide, to facilitate understanding of the article. To view digital features for this article go to https://doi.org/10.6084/ m9.figshare.14617254.

\section{INTRODUCTION}

Severe acute respiratory syndrome coronavirus 2 (SARS-Cov-2) causes a respiratory illness designated as coronavirus disease 2019 (COVID-19) and has resulted in a global pandemic. In the beginning of December 2020, the World Health Organization (WHO) registered almost 70 million cases of COVID-19 and more than 1.5 million deaths worldwide [1]. Spain is one of the European countries more severely affected by the ongoing pandemic [2], with more than 1.7 million cases of COVID-19 and close to 50,000 deaths at the end of 2020 [1].

The COVID-19 pandemic resulted in a significant burden on the Spanish National Health System (SNHS) due to dramatically increased hospitalizations [3]. In the worst times of the pandemic, hospitals were forced to expand the number of beds available for COVID-19 patients in improvised ward areas [4]. In addition, the management of an increasing number of cases and the need for preventive measures delayed diagnosis, treatment, monitoring, and nonemergency surgeries of other patients [5-7]. Furthermore, due to the concerns about the risk of COVID-19 infection, some patients avoided going to healthcare centers and hospitals, increasing the morbidity and mortality of other acute and chronic health conditions [8].

In July 2020, remdesivir received conditional marketing authorization from the European Medicines Agency [9], becoming the first drug indicated for the treatment of COVID-19. The pivotal study (ACTT-1) showed that remdesivir improves the time to recovery, reducing the length of hospital stay in patients with COVID19 and pneumonia who require supplemental oxygen [10]. Remdesivir also showed a reduction in disease progression, reducing the incidence of the need for new oxygen, high-flow 
oxygen, and mechanical ventilation. Moreover, non-mechanically ventilated patients had a slower progression or reduced mortality with respect to placebo according to the post hoc analysis. Considering the dramatic situation that occurred in Spain, the aim of our study was to estimate the impact that remdesivir would have had during the first wave of the COVID-19 pandemic.

\section{METHODS}

This retrospective study used an epidemiological model to estimate the potential impact of remdesivir on hospital stays, mortality, and subsequent resource use and costs to the SNHS during the first wave of the COVID-19 pandemic (from 31 January 2020 to 10 May 2020). Two scenarios were considered: a real-life scenario (without remdesivir) and an alternative scenario (with remdesivir) (Fig. 1). According to Spanish law ("Ley 14/2007, de 3 de julio, de Investigación biomédica") ethical approval was not applicable for this study.

\section{Data Resources}

Epidemiology data and mortality rates were collected from the reports published by the Instituto de Salud Carlos III, under the Ministry of Health. Healthcare resource use was obtained from a literature review; international references were used whenever national data were not available. Databases consulted were MEDLINE/PubMed, Medes, and other official databases. All extracted data were validated by an expert group comprising four infectious disease specialists, an intensive care specialist, a medical microbiologist, and a hospital pharmacist.

\section{Population}

During the first wave, 233,328 patients with COVID-19 were diagnosed in Spain [11]. As reported by the Instituto de Salud Carlos III, $46.13 \%$ of COVID-19 patients were hospitalized [11], and the prevalence of pneumonia was $83.84 \%$ [12]. Hence, it was estimated that
$38.68 \%$ of all patients with COVID-19 had to be hospitalized because of COVID-19 and pneumonia and $7.45 \%$ were hospitalized because of other disorders $[11,12]$. Of those hospitalized with pneumonia, it was estimated that $76.10 \%$ required supplemental oxygen (Supplementary material, Fig. 1) [13].

Of the patients requiring supplemental oxygen, $80.63 \%$ received low-flow oxygen therapy (19.37\% received other types of oxygen support). Moreover, $10.70 \%$ of patients were admitted directly to an intensive care unit (ICU), with $89.30 \%$ of patients being admitted to a general ward (Supplementary material, Fig. 1) [12]. The model assumes that these patients would have been eligible for remdesivir treatment using current SNHS guidance [14].

\section{Resource Use}

This study considered the length of hospital stay and the number of hospitalized patients in general wards and ICUs during the first wave of the COVID-19 pandemic.

Patients were admitted to hospitals at a median of 6 (interquartile range [IQR] 3-9) days from the onset of symptoms [12]. The average hospital stay lasted an average of 10.40 (range 1-62) days [15]. As ICU admissions lasted an average of 23.00 days [16], admissions to general hospital wards were estimated to last an average of 8.89 days $[12,15,16]$. However, remdesivir has been shown to reduce recovery time in hospitalized patients with COVID-19 and supplemental oxygen with respect to placebo patients (rate ratio [RR] 1.45; 95\% confidence interval [CI] 1.18-1.79) [10]. Therefore, it was estimated that remdesivir would have reduced hospital stay in general wards by up to 6.13 days (95\% CI 4.97-7.53) [10, 12, 15, 16].

In addition, remdesivir has been shown to improve the clinical status of hospitalized patients with COVID-19 and pneumonia who require supplemental oxygen. The probability of needing mechanical ventilation, high-flow oxygen devices, or extracorporeal membrane oxygenation (ECMO) at 15 days, was lower in patients treated with remdesivir compared to those in the placebo group (7.76\% vs. $13.79 \%)$ 
[10]. A chi-square test of independence (significance level 95\%) was performed to test whether there was a difference in the proportion of patients admitted to the ICU between the remdesivir and placebo groups. This analysis showed a significant difference in the proportion of patients $(p=0.04236)$. Therefore, as patients who require mechanical ventilation, high-flow oxygen devices, or ECMO are assisted in ICUs in Spain, we assumed that remdesivir would have reduced the number of patients hospitalized in ICUs (RR: 0.56; 95\% CI $0.49-0.61$ ) by $6.02 \%$ (95\% CI $5.19 \%-6.53 \%$ ) (Supplementary material, Fig. 1).

\section{Occupancy Rates}

The number of patients and the length of hospital stay allowed us to estimate the number of occupied beds in general hospital wards and ICUs. According to the Ministry of Health, there are 3566 beds in ICUs and 112,219 beds in the public healthcare system [17]. Therefore, the occupancy rate was estimated in both scenarios over the whole capacity of the SNHS in terms of total hospital beds and ICU beds.

\section{Mortality}

During the first wave of the pandemic, $11.90 \%$ of patients with COVID-19 died. The mortality rate in patients hospitalized in general wards was $20.61 \%$, while it was $25.72 \%$ for those in ICUs [12]. In hospitalized patients, the duration of the period ranging from the onset of symptoms until death was estimated at a median of 11 (IQR: 7-18) days [12]; accordingly, the time patients had been in the hospital was estimated at 5 days. In the ACTT-1 trial, remdesivir reduced mortality by $70 \%$ (RR: $0.30 ; 95 \%$ CI 0.14-0.64) in hospitalized patients with COVID19 and supplemental oxygen [10]. This risk ratio

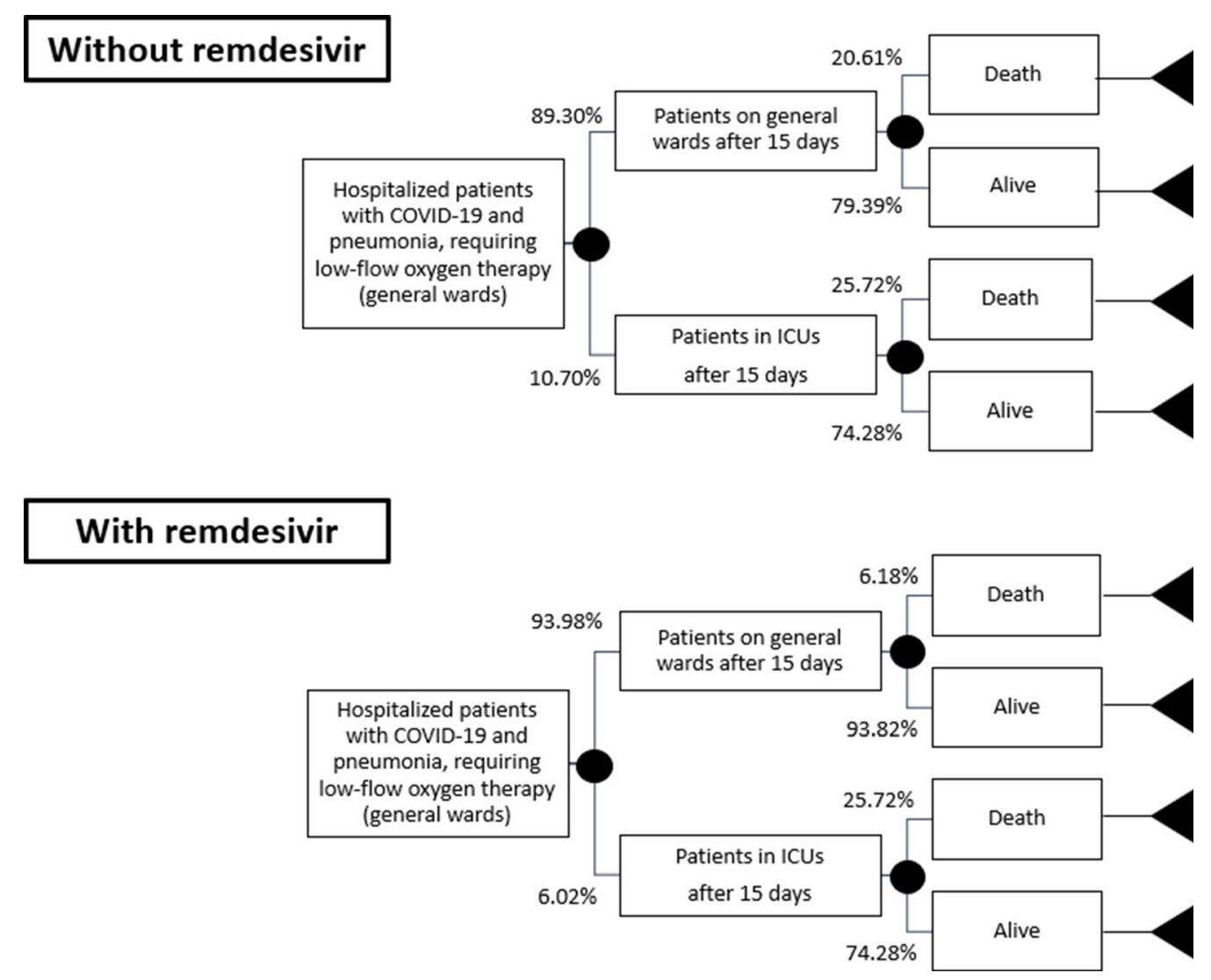

Fig. 1 Scheme of the decision model. ICUs intensive care units 
was applied to the government mortality data to calculate the potential impact of remdesivir on the mortality rate in patients on low-flow oxygen (a reduction of up to $6.18 \%$ [95\% CI $2.89 \%-13.19 \%]$ in general hospital wards) (Fig. 1) [10, 12]. The mortality rate per age group and the number of patients necessary to treat (NNT) with remdesivir to prevent a COVID-19 death were also estimated.

\section{RESULTS}

\section{Population}

The incidence of COVID-19 during the first wave, in the real-life setting, is shown in Fig. 2. Most of the cases were registered between March and April 2020, reaching a maximum of 10,140 patients on 25 March. Five days later, the peak number of hospitalized patients admitted to the general wards was recorded $(n=4209)$. Moreover, the maximum number of patients admitted into ICUs $(n=469)$ was recorded on 2 and 3 April.

In the real-life scenario, of the 55,372 hospitalized patients with COVID-19 and pneumonia receiving low-flow oxygen therapy, 5919 were referred to the ICUs after 15 days because of worsening of the disease. However, in the alternative scenario, 3332 patients (95\% CI 2872-3618) would have been referred to these units. Therefore, remdesivir would have prevented the admission of 2587 patients (95\% CI 2301-3047) into ICUs, which is a reduction of $43.71 \%$ (95\% CI 38.87\%-51.48\%) in the number of patients hospitalized in ICUs (Table 1).

\section{Occupied Beds}

The maximum occupancy of beds reserved for COVID-19 patients in general hospital wards was registered on 5 April, reaching 32,264 occupied beds. However, as remdesivir reduces the length of hospital stay, 5656 hospital beds (95\% CI 1283-7880) would have been made available for other patients on that date. Accordingly, the number of available beds would have increased by $17.53 \%$ (95\% CI
$3.98 \%-24.42 \%)$ at the time of the highest occupancy rate. The green area (Fig. 3) shows the number of beds that would have been released per day if remdesivir had been available since the beginning of the first wave.

Regarding ICUs, the highest occupancy records were registered on 17 April 2020, reaching 7088 occupied beds. As remdesivir improves the clinical status of patients with COVID-19 and pneumonia who require lowflow oxygen therapy, this new drug would have made 1700 (95\% CI 1512-2000) beds available for other patients on that date. Therefore, the number of available beds would have increased by $23.98 \%$ (95\% CI $21.33 \%-28.22 \%$ ) during the peak ICU occupancy rate (Fig. 4).

\section{Mortality}

During the first wave, 10,189 patients and 1524 patients died in general hospital wards and ICUs, respectively. However, as remdesivir was shown to reduce the mortality rate in hospitalized patients with COVID-19 and pneumonia receiving low-flow oxygen therapy, this new drug could have prevented 6972 deaths (95\% CI 3364-8675) in general wards. Furthermore, it was estimated that remdesivir could have prevented at least half of the ICU admissions, potentially preventing an additional 667 deaths (95\% CI 594-785) (Table 1).

In the 'no remdesivir' scenario, the overall mortality rate in hospitalized patients with COVID-19 and pneumonia who require lowflow oxygen therapy was estimated to be $21.15 \%$. In the 'remdesivir' scenario, the mortality rate was estimated at $7.36 \%(95 \% \mathrm{CI}$ 4.07\%-14.01\%), which represents an absolute risk reduction of death of $13.80 \%$ (95\% CI 7.15\%-17.08\%). Accordingly, seven hospitalized patients (95\% CI 6-14) with COVID-19 and pneumonia who required low-flow oxygen therapy needed to be treated with remdesivir to prevent one death.

We estimated that another 16,053 patients with COVID-19 died in the first wave (i.e., nonhospitalized patients, hospitalized patients with pneumonia who did not require low-flow oxygen, and hospitalized patients with other 
disorders different from pneumonia). Therefore, in the remdesivir scenario, the number of deaths was estimated to be 20,128 (95\% CI $18,307-23,809)$, avoiding 7639 deaths (95\% CI $3958-9460)$, which implies a $27.51 \%$ reduction (95\% CI $14.25 \%-34.07 \%)$ in the mortality rate due to COVID-19 (Tables 1 and 2).

Table 2 shows that mortality rates increased by age. As can be seen, the number of deaths amounted to 6619 and 17,371 in patients between 70-79 and over 80 years, respectively, in the real-life scenario. However, remdesivir could have prevented 1821 deaths (95\% CI 943-2255) and 4779 deaths (95\% CI 2476-5918) in both groups, respectively.

\section{DISCUSSION}

The COVID-19 pandemic has placed a significant burden on healthcare systems. The rising number of cases has increased the use of resources, leading to drug shortages and an insufficient number of hospital beds [4]. To expand the capacity of the SNHS, some temporary field hospitals were opened, such as the pavilions of the city fair in Madrid [3]. Furthermore, given the lack of resources, only those patients with pneumonia who were in serious condition were hospitalized during the peak of the pandemic. Most COVID-19 patients were sent to nearby adapted hotels or their own homes to be treated by general practitioners [4, 18].

Our results showed that the maximum number of hospitalized patients with this infection was reached on 5 April 2020 when 32,264 beds were occupied in general hospital wards and on 17 April when 7088 beds were occupied in ICUs. In line with our research, the Institute for Health Metrics and Evaluation (IHME) estimated that the maximum number of occupied beds in general wards was 46,081 on 31 March and 6430 beds in ICUs on 4 April. However, the studies differ in their methodology, as we estimated the healthcare resource use according to official records and observational studies carried out in Spain, while the IHME developed a microsimulation model based on death reports [19].

According to our research, the capacity of the ICUs almost doubled during the first wave, as the bed occupancy rate reached $198.77 \%$. This dramatic situation prompted the development of a contingency plan by the Spanish Society of Critical, Intensive, and Coronary Medicine Units (SEMICYUC) and other intensive medicine organizations. The new program was based on increasing the number of ICU beds and other healthcare resources to avoid the

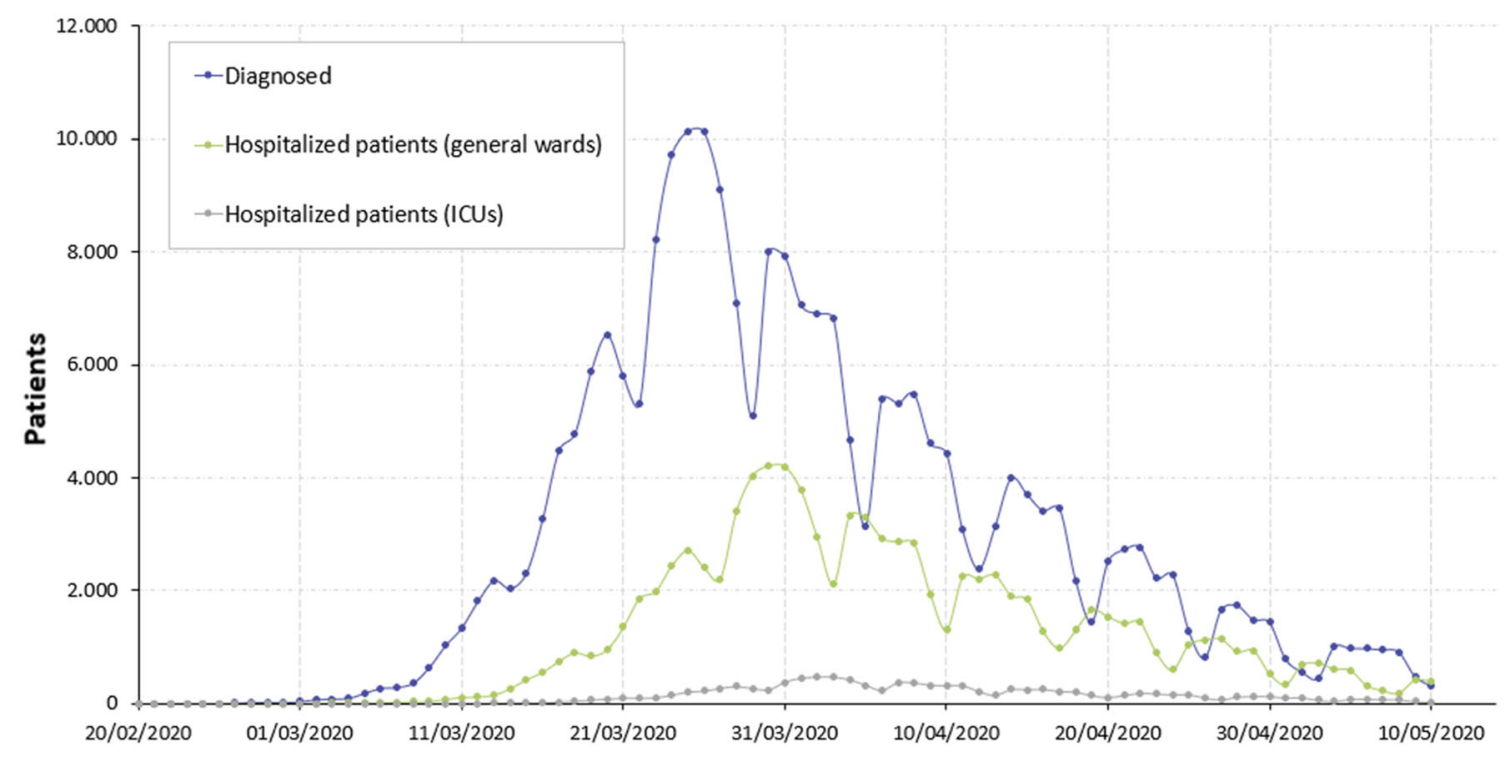

Fig. 2 Incident COVID-19 patients during the first wave in Spain. ICUs intensive care units 
Table 1 Hospitalized patients and deaths in both scenarios

\begin{tabular}{|c|c|c|c|}
\hline & $\begin{array}{l}\text { Without } \\
\text { remdesivir (n) }\end{array}$ & $\begin{array}{l}\text { With remdesivir (Mean; } \\
\text { 95\% CI) }\end{array}$ & Difference (Mean; 95\% CI) \\
\hline Hospitalized patients* & & & - \\
\hline On general wards after 15 days & 49,453 & $\begin{array}{l}52,040(95 \% \text { CI } \\
51,754-52,500)\end{array}$ & 2587 (95\% CI 2301-3047) \\
\hline ICUs after 15 days & 5919 & 3332 (95\% CI 2872-3618) & $\begin{array}{l}-2587(95 \% \mathrm{CI}-3047 \text { to } \\
[-2301])\end{array}$ \\
\hline \multicolumn{4}{|l|}{ Deaths } \\
\hline On general wards & 10,189 & 3217 (95\% CI 1515-6826) & $\begin{array}{l}-6972(95 \% \mathrm{CI}-8675 \text { to } \\
[-3364])\end{array}$ \\
\hline ICUs & 1524 & 857 (95\% CI 739-930) & $\begin{array}{l}-667(95 \% \text { CI }-785 \text { to } \\
[-594])\end{array}$ \\
\hline $\begin{array}{l}\text { Deaths (other COVID-19 } \\
\text { patients) }^{* *}\end{array}$ & 16,053 & & NA \\
\hline Total & 27,767 & $\begin{array}{r}20,128(95 \% \text { CI } \\
18,307-23,809)\end{array}$ & $\begin{array}{l}-7639(95 \% \mathrm{CI}-9460 \text { to } \\
[-3958])\end{array}$ \\
\hline
\end{tabular}

${ }^{*}$ Hospitalized patients with COVID-19 and pneumonia requiring low-flow oxygen therapy at the time of hospitalization. This is the target population for the treatment with remdesivir

${ }^{* *}$ Non-hospitalized patients, hospitalized patients with pneumonia who did not require low-flow oxygen and hospitalized patients with other disorders different from pneumonia

NA not aplicable. Sources: Instituto de Salud Carlos III. Informe no 33, 2020 [12]

breakdown of the SNHS in the following waves and future pandemics [20]. In consonance with these recommendations, Lacasa and colleagues estimated an algorithm to provide optimal rerouting strategies for ICUs patients [21]. Their approach was validated using reallife data from Spain; they concluded that 600 beds could have been made available using local sharing and over 1300 beds with countrywide sharing. This strategy would improve the management of COVID-19, particularly for patients who would not otherwise have access to ICUs. However, their approach had some limitations, as they considered the transportation of unstable patients in mobile ICUs and an unlimited number of ambulances and human resources [21]. Moreover, the mortality rate in hospitalized patients on general wards was $20.61 \%$ [12], which is in line with a previous study reporting a mortality rate of $21.01 \%$ in hospitalized patients with COVID-19 [15].

The efficacy of remdesivir in the management of COVID-19 has been demonstrated in several studies [9]. Olender and colleagues analyzed its efficacy in a non-randomized cohort study using a propensity score model and an inverse probability of the treatment weighting method. The participants were hospitalized patients with COVID-19, pulmonary infiltrates and either had oxygen saturation of $\leq 94 \%$ on room air or were receiving supplemental oxygen. Their results showed that $74.40 \%$ of patients in the remdesivir group versus $59.00 \%$ in the standard of care group achieved the primary recovery endpoint at day 14 (adjusted odds ratio: 2.03 [95\% CI 1.34-3.08], $p<0.001$ ). They also observed a $62 \%$ lower adjusted odds of all-cause death [22]. In addition, the doubleblind, randomized, and placebo-controlled 


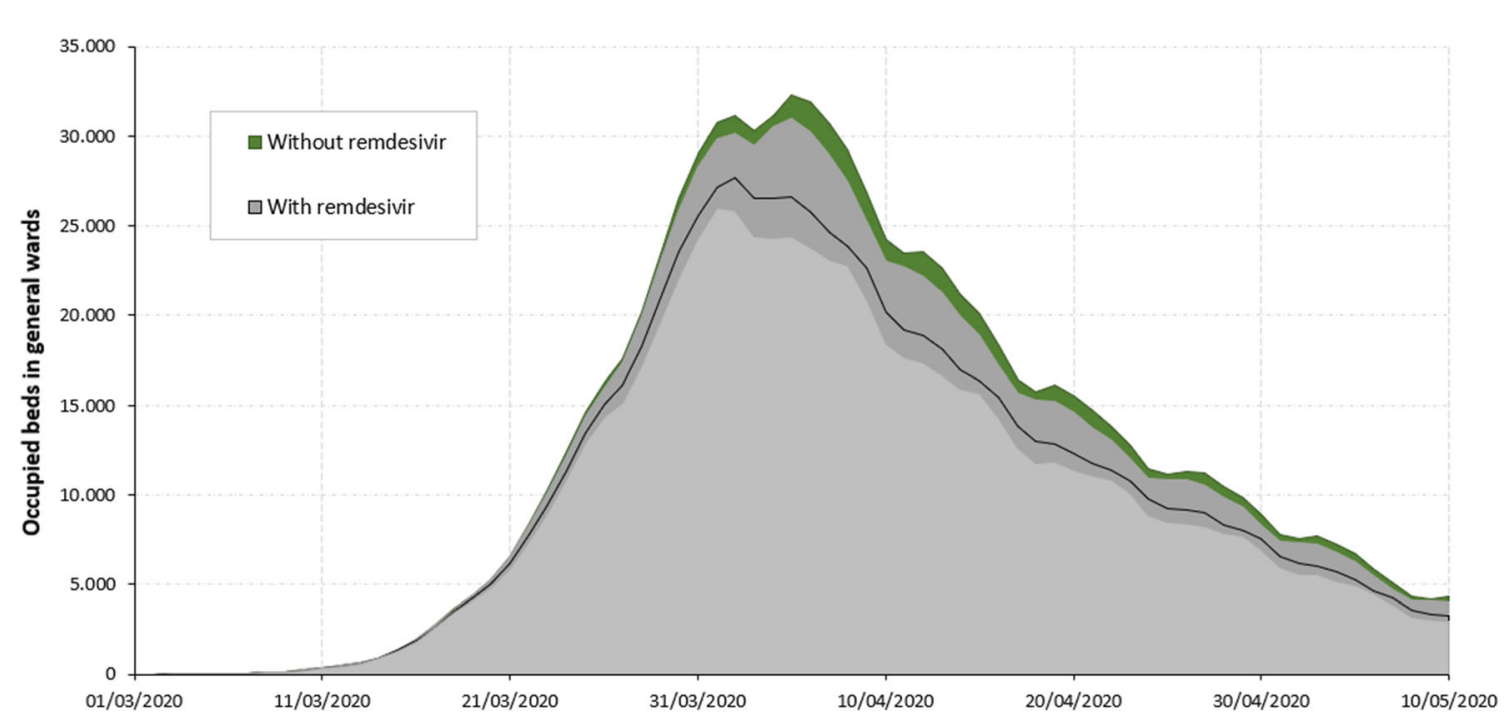

Fig. 3 Occupied beds in general wards in both scenarios. Note: The number of days in general wards without and with remdesivir was 876,018 and 741,858 (95\% CI 840,258-692,378), respectively

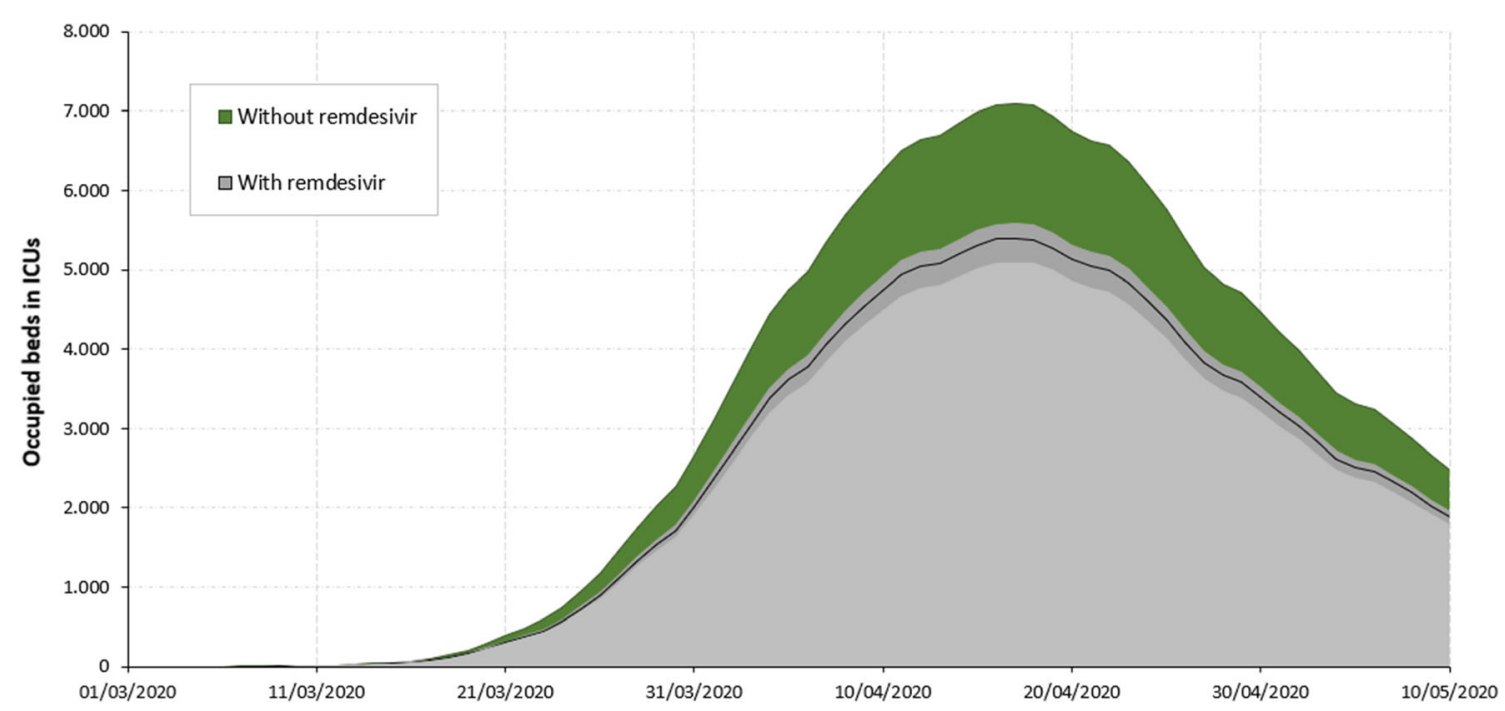

Fig. 4 Occupied beds in ICUs in both scenarios. ICUs intensive care units. Note: The number of days in ICUs without and with remdesivir was 220,884 and 167,923 (95\% CI 173,796-158,540), respectively

ACTT-1 trial showed that remdesivir improves the time to recovery and clinical status of hospitalized patients with COVID-19 and pneumonia who require supplemental oxygen [10], resulting in a reduction in the length of hospital stay and the number of ICU admissions. Despite the fact that the ACTT-1 trial did not reach a statistically significant difference in mortality in the overall study population, a post hoc analysis showed that remdesivir significantly reduced the mortality in hospitalized patients with COVID-19 and supplemental oxygen.

Our results showed that remdesivir would have made up to 7880 beds available in general wards and 2000 ICU beds for other patients at the peak of the occupancy rates. Therefore, this new drug could have relieved the pressure of the pandemic on hospitals and the SNHS. Furthermore, remdesivir could have implied a $27.51 \%$ reduction (95\% CI 14.25\%-34.07\%) in deaths 
Table 2 Total deaths (general wards and ICUs) by age group

\begin{tabular}{|c|c|c|c|c|c|c|c|}
\hline \multirow{2}{*}{$\begin{array}{l}\text { Age } \\
\text { (years) }\end{array}$} & \multirow{2}{*}{$\begin{array}{l}\text { Without } \\
\text { remdesivir }\end{array}$} & \multicolumn{3}{|c|}{ With remdesivir } & \multicolumn{3}{|c|}{ Difference } \\
\hline & & Average & $\begin{array}{l}95 \% \text { CI } \\
\text { (inferior) }\end{array}$ & $\begin{array}{l}95 \% \text { CI } \\
\text { (superior) }\end{array}$ & Average & $\begin{array}{l}95 \% \mathrm{CI} \\
\text { (inferior) }\end{array}$ & $\begin{array}{l}95 \% \mathrm{CI} \\
\text { (superior) }\end{array}$ \\
\hline$<2$ & 3 & 2 & 2 & 2 & 1 & 0 & 1 \\
\hline $2-4$ & 0 & 0 & 0 & 0 & 0 & 0 & 0 \\
\hline $5-14$ & 1 & 1 & 1 & 1 & 0 & 0 & 0 \\
\hline $15-29$ & 38 & 27 & 25 & 32 & 10 & 5 & 13 \\
\hline $30-39$ & 85 & 62 & 56 & 73 & 23 & 12 & 29 \\
\hline $40-49$ & 294 & 213 & 194 & 252 & 81 & 42 & 100 \\
\hline $50-59$ & 891 & 646 & 587 & 764 & 245 & 127 & 303 \\
\hline $60-69$ & 2466 & 1788 & 1626 & 2115 & 678 & 351 & 840 \\
\hline $70-79$ & 6619 & 4798 & 4364 & 5675 & 1821 & 943 & 2255 \\
\hline$\geq 80$ & 17,371 & 12,592 & 11,453 & 14,895 & 479 & 2476 & 5918 \\
\hline Total & 27,767 & 20,128 & 18,307 & 23,809 & 7639 & 3958 & 9460 \\
\hline
\end{tabular}

$C I$ confidence interval; $I C U s$ intensive care units

due to COVID-19 during the first wave in Spain. It should be noted that a multi-country, openlabel, randomized trial developed by WHO showed that the mortality rate for hospitalized patients with COVID-19 did not achieve statistical significance $(\mathrm{RR}=0.95$ [95\% CI 0.81-1.11], $p=0.50)$ [23]. Although this conclusion differs from previous evidence, it should be noted that our results refer to those patients who required low-flow oxygen therapy (a National Early Warning Score [NEWS] of 5) [24] according to the pharmacological protocol used in the SNHS [14]. In addition, the SOLIDARITY trial compared the efficacy of remdesivir in patients with or without mechanical ventilation, regardless of the oxygen delivery system (e.g., low- or highflow devices) [23]. A recent systematic review and meta-analysis also concluded that remdesivir is more effective and safe than standard treatment because it is associated with a faster time to clinical improvement, a reduction in mortality rate, and reduced incidence of serious adverse events [25].

Our study has some limitations that need to be addressed. First, due to the lack of information about the clinical status of COVID19 patients, we assumed that $76.10 \%$ of hospitalized patients with pneumonia required supplemental oxygen, according to the US records [13]. Nevertheless, a group of experts agreed that this percentage was similar to the clinical practice in Spain. Second, we considered that hospitalized patients who require mechanical ventilation, high-flow oxygen devices, or ECMO are assisted in ICUs in Spain. Although this practice is widely spread, the management of COVID-19 patients may differ in some Spanish regions. Third, since there are no real-life studies about the efficacy of remdesivir in our country, we assumed the results of the ACTT-1 trial. Fourth, although we considered official sources, our results may be biased because of notification delays and the overwhelmed healthcare system. Fifth, given that the reduction of mortality rates by age group in patients receiving remdesivir was not estimated in the ACTT-1 trial, we estimated the number of prevented deaths by age group using the reduction in the mortality rate for the whole population of the trial. Sixth, since the potential impact on 
mortality due to the controversial use of other drugs, such as IL6 inhibitors, is unknown, it was not considered in our study. In addition, there is uncertainty about remdesivir's benefit in terms of mortality in low-flow oxygen therapy patients because of the limitation of a post hoc analysis. Nevertheless, aspects such as the fact that the overall mortality, significant in the total study population of the ACTT-1 trial, reflects the huge COVID-19 heterogeneity in behavior in different patient subgroups and the difficulty of randomizing benefits coming from the highest sample size subgroup $(n=232$ in remdesivir group and $n=203$ in placebo group) should be taken into account [10]. Furthermore, in a real-life cohort of patients with severe pneumonia receiving low-flow oxygen-therapy treated with remdesivir, the 30-day mortality rate observed was $4.1 \%$ [26], very similar to that reported in the ACTT-1 trial [10]. This suggests that the results observed in this study could be in line with reality.

Despite these limitations, the main contributions of our study are: (1) the assessment of the healthcare resources used during the first wave of the pandemic (in terms of occupied beds in general wards and ICUs) in Spain and (2) the potential number of beds that could have been available in general wards and ICUs if remdesivir had been used for the treatment of COVID-19. Our results showed that this new drug would have prevented almost half of the ICU admissions, reducing the pressure on the public healthcare system, thus providing a more efficient use of resources. Consequently, in the following waves of the pandemic, the preventive measurements and vaccines have reduced the burden of COVID-19 for the SNHS as well as the death toll [27]. Given the mistrust in vaccines and concerns about future side effects $[28,29]$, remdesivir may reduce the healthcare resource burden and potentially avoid preventable deaths.

\section{CONCLUSIONS}

The treatment with remdesivir in hospitalized patients with COVID-19 and pneumonia who require low-flow oxygen therapy, could have reduced the number of occupied beds in hospital wards and ICUs by $17.53 \%$ and $23.98 \%$, respectively. Therefore, it could have reduced the pressure on the SNHS during the first wave, providing a better strategy for the management of COVID-19 in our country. Furthermore, remdesivir could have prevented $27.51 \%$ of deaths due to this infection. Therefore, in the future, the use of remdesivir in COVID-19 patients admitted with pneumonia and lowflow oxygen therapy could help reduce the burden of COVID-19 on the SNHS.

\section{ACKNOWLEDGEMENTS}

Funding. This work was supported by Gilead Sciences. Gilead Sciences also funded the journal's Rapid Service and Open Access Fees.

Authorship. All named authors meet the International Committee of Medical Journal Editors (ICMJE) criteria for authorship for this article, take responsibility for the integrity of the work as a whole, and have given their approval for this version to be published.

Authors' contributions. Antonio CastroGómez and Almudena González-Domínguez participated in the conception and design of the study. Alejandro Soriano, Rocío Montejano, José Sanz-Moreno, Santiago Grau, Robert Güerri-Fernández, Inés Pérez-Román, and Almudena González-Domínguez participated in the acquisition of data. Antonio Castro-Gómez, Inés Pérez-Román, Álvaro Hidalgo-Vega and Almudena González-Domínguez participated in the analysis and interpretation of data. Inés Pérez-Román wrote the draft of the manuscript. All authors critically revised the manuscript for important intellectual content and approved the final version to be published.

Disclosures. Alejandro Soriano reports grants and personal fees from Pfizer and Gilead Sciences and personal fees from Merck, Shionogi, and Menarini outside the submitted work. Rocío Montejano reports honorarium from Gilead Sciences, during the conduct of the 
study, and personal fees from Gilead Sciences, ViiV, Merck Sharp and Dohme, and Janssen Cilag outside the submitted work. Santiago Grau reports personal fees from Gilead Sciences during the conduct of the study; personal fees from Gilead Sciences, Pfizer, and MSD outside the submitted work. Robert Güerri-Fernández reports grants and honorarium for research from Gilead Sciences and honorarium for consulting from ViiV outside the submitted work. Antonio Castro-Gómez is a Gilead Sciences employee. Almudena González-Domínguez and Inés Pérez-Román work at Weber, a company that received fees from Gilead Sciences, during the conduct of the study. Álvaro Hidalgo-Vega, Juan Carlos Figueira, and José Sanz-Moreno have nothing to disclose.

Compliance with Ethics Guidelines. According to Spanish law ("Ley 14/2007, de 3 de julio, de Investigación biomédica") ethical approval was not applicable for this study.

Data Availability. Data sharing is not applicable to this article as no datasets were generated or analyzed during the current study.

Open Access. This article is licensed under a Creative Commons Attribution-NonCommercial 4.0 International License, which permits any non-commercial use, sharing, adaptation, distribution and reproduction in any medium or format, as long as you give appropriate credit to the original author(s) and the source, provide a link to the Creative Commons licence, and indicate if changes were made. The images or other third party material in this article are included in the article's Creative Commons licence, unless indicated otherwise in a credit line to the material. If material is not included in the article's Creative Commons licence and your intended use is not permitted by statutory regulation or exceeds the permitted use, you will need to obtain permission directly from the copyright holder. To view a copy of this licence, visit http://creativecommons.org/licenses/by$\mathrm{nc} / 4.0 /$.

\section{REFERENCES}

1. WHO Coronavirus Disease (COVID-19) Dashboard [Internet]. 2020 [cited 2020 Nov 10]. Available from: https://covid19.who.int

2. Pollán M, Pérez-Gómez B, Pastor-Barriuso R, Oteo J, Hernán MA, Pérez-Olmeda $M$, et al. Prevalence of SARS-CoV-2 in Spain (ENE-COVID): a nationwide, population-based seroepidemiological study. The Lancet. 2020;396:535-44.

3. Miralles O, Sanchez-Rodriguez D, Marco E, Annweiler C, Baztan A, Betancor E, et al. Unmet needs, health policies, and actions during the COVID-19 pandemic: a report from six European countries. Eur Geriatr Med [Internet]. 2020 [cited 2020 Nov 17]; Available from: http://link.springer.com/https://doi.org/10.1007/s41999-020-00415-

4. Arango C. Lessons learned from the coronavirus health crisis in Madrid, Spain: how COVID-19 has changed our lives in the last 2 weeks. Biol Psychiatry. 2020;88:e33-4.

5. Legido-Quigley H, Mateos-García JT, Campos VR, Gea-Sánchez M, Muntaner C, McKee M. The resilience of the Spanish health system against the COVID-19 pandemic. Lancet Public Health Elsevier. 2020;5:e251-2.

6. Petrova D, Pérez-Gómez B, Pollán M, Sánchez M-J. Implications of the COVID-19 pandemic for cancer in Spain. Med Clin Engl Ed. 2020;155:263-6.

7. Dejaco C, Alunno A, Bijlsma JW, Boonen A, Combe $B$, Finckh A, et al. Influence of COVID-19 pandemic on decisions for the management of people with inflammatory rheumatic and musculoskeletal diseases: a survey among EULAR countries. Ann Rheum Dis [Internet]. BMJ Publishing Group Ltd; 2020 [cited 2020 Nov 12]; Available from: https:// ard.bmj.com/content/early/2020/11/06/ annrheumdis-2020-218697

8. Rodríguez-Leor O, Cid-Álvarez B, Ojeda S, MartínMoreiras J, Ramón Rumoroso J, López-Palop R, et al. Impact of the COVID-19 pandemic on interventional cardiology activity in Spain. REC Interv Cardiol Engl Ed. 2020;2:82-9.

9. European Medicines Agency (EMA). Ficha técnica Veklury $100 \mathrm{mg}$ concentrado para solución para perfusión. [Internet]. 2020 [cited 2021 Jan 14]. Available from: https://cima.aemps.es/cima/ dochtml/ft/1201459001/FT_1201459001.html

10. Beigel JH, Tomashek KM, Dodd LE, Mehta AK, Zingman BS, Kalil AC, et al. Remdesivir for the 
treatment of Covid-19 - preliminary report. N Engl J Med. 2020;383:1813-26.

11. Instituto de Salud Carlos III (ISCIII). Situación y evolución de la pandemia de COVID-19 en España. [Internet]. [cited 2020 Jul 21]. Available from: https://cnecovid.isciii.es/covid19/\#documentaci\% C3\%B3n-y-datos

12. Instituto de Salud Carlos III (ISCIII). Informe $\mathrm{n}^{\mathrm{o}} 33$. Análisis de los casos de COVID-19 hasta el 10 de mayo. Informe COVID-19. 9 de diciembre de 2020. [Internet]. 2020 [cited $2020 \mathrm{Jul}$ 7]. Available from: https://www.isciii.es/QueHacemos/Servicios/Vigilan ciaSaludPublicaRENAVE/EnfermedadesTransmisibles/ Documents/INFORMES/Informes\%20COVID-19/ Informe $\% 20 \mathrm{n} \% \mathrm{C} 2 \% \mathrm{BA} \% 2033 . \% 20 \mathrm{An} \% \mathrm{C3} \% \mathrm{~A} 1 \mathrm{lisis}$ \%20de\%20los\%20casos\%20de\%20COVID-19\%20 hasta\%20el\%2010\%20de\%20mayo\%20en\%20Espa \%C3\%B1a\%20a\%2029\%20de\%20mayo\%20de\% 202020.pdf

13. Gold JAW. Characteristics and clinical outcomes of adult patients hospitalized with COVID-19 Georgia, March 2020. MMWR Morb Mortal Wkly Rep. 2020;69:545-50.

14. Ministerio de Sanidad, Consumo y Bienestar Social. Protocolo farmacoclínico del uso de Vekluri ${ }^{\circledR}$ en el tratamiento de la enfermedad por COVID-19 en el Sistema Nacional de Salud (SNS) [Internet]. 2020. Available from: https://www.mscbs.gob.es/ profesionales/farmacia/valtermed/home.htm

15. Casas Rojo JM, Antón Santos JM, Millán NúñezCortés J, Lumbreras Bermejo C, Ramos Rincón JM, Roy-Vallejo E, et al. Clinical characteristics of patients hospitalized with COVID-19 in Spain: results from the SEMI-COVID-19 Network. [Internet]. Infectious Diseases (except HIV/AIDS); 2020. Available from: http://medrxiv.org/lookup/doi/ https://doi.org/10.1101/2020.05.24.20111971

16. Corregidor-Luna L, Hidalgo-Correas FJ, García-Díaz B. Gestión farmacéutica de la pandemia COVID-19 en un hospital mediano. Farm Hosp. 2020;44:11-6.

17. Ministerio de Sanidad. Estadísticas de Centros Sanitarios de Atención Especializada. Hospitales y Centros sin Internamiento. Información y estadísticas sanitarias. [Internet]. 2018. Available from: https://www.mscbs.gob.es/estadEstudios/ estadisticas/estHospiInternado/inforAnual/ homeESCRI.htm

18. Han E, Tan MMJ, Turk E, Sridhar D, Leung GM, Shibuya K, et al. Lessons learnt from easing COVID19 restrictions: an analysis of countries and regions in Asia Pacific and Europe. The Lancet Elsevier. 2020;396:1525-34.
19. IHME | COVID-19 Projections [Internet]. Inst. Health Metr. Eval. 2020 [cited 2020 Nov 16]. Available from: https://covid19.healthdata.org/

20. SeMicyuc, SEEIUC, FEPIMCTI. Plan de desescalada para los servicios de medicina intensiva tras la pandemia producida por la COVID-19 [Internet]. [cited 2020 Jul 22]. Available from: https:// semicyuc.org/wp-content/uploads/2020/07/PLANDESESCALADA-SEMICYUC-SEEIUC-FEPIMCTI.pdf

21. Lacasa L, Challen R, Brooks-Pollock E, Danon L. A flexible method for optimising sharing of healthcare resources and demand in the context of the COVID-19 pandemic. Rahman MS, editor. PLOS ONE. 2020;15:e0241027

22. Olender SA, Perez KK, Go AS, Balani B, Price-Haywood EG, Shah NS, et al. Remdesivir for Severe COVID-19 versus a Cohort Receiving Standard of Care. Clin Infect Dis Off Publ Infect Dis Soc Am. 2020. https://doi.org/10.1093/cid/ciaa1041.

23. Consortium WS trial, Pan H, Peto R, Karim QA, Alejandria M, Henao-Restrepo AM, et al. Repurposed antiviral drugs for COVID-19 -interim WHO SOLIDARITY trial results. N Engl J Med. 2021;384: 497-511.

24. Bilben B, Grandal L, Søvik S. National Early Warning Score (NEWS) as an emergency department predictor of disease severity and 90-day survival in the acutely dyspneic patient - a prospective observational study. Scand J Trauma Resusc Emerg Med [Internet]. 2016 [cited 2021 Jan 14];24. Available from: https://www.ncbi.nlm.nih.gov/pmc/articles/ PMC4890514/

25. Timotius IH, Felix K, Karunia VJ, Vika D, Andree K. The Effectiveness and safety of remdesivir for the treatment of patients with COVID-19: a systematic review and meta-analysis. Anti-Infect Agents. 2021;19:333-40.

26. Garcia-Vidal C, Meira F, Cózar-Llistó A, Dueñas G, Puerta-Alcalde P, Garcia-Pouton N, et al. Real-life use of remdesivir in hospitalized patients with COVID-19. Rev Esp Quimioter. 2021;34:136-40.

27. European Centre for Disease Prevention and Control. Guidelines for the implementation of nonpharmaceutical interventions against COVID-19 [Internet]. 2020 [cited 2020 Nov 30]. Available from: https://www.ecdc.europa.eu/en/publicationsdata/covid-19-guidelines-non-pharmaceuticalinterventions

28. Paul E, Steptoe A, Fancourt D. Attitudes towards vaccines and intention to vaccinate against COVID19: Implications for public health communications. Lancet Reg Health Eur [Internet]. 2021 [cited 2021 
May 11];1. Available from: https://www.ncbi.nlm. nih.gov/pmc/articles/PMC7834475/

29. World Health Organization. Behavioural considerations for acceptance and uptake of COVID-19 vaccines [Internet]. 2020 [cited 2021 May 11]. Available from: https://apps.who.int/iris/bitstream/ handle/10665/337335/9789240016927-eng. pdf? sequence $=1 \&$ is Allowed $=\mathrm{y}$ 